\title{
A transnational bicultural place model of cultural selves and psychological citizenship: The case of Chinese immigrants in Britain
}

\section{Introduction}

Place is a central concept in humanistic geography, sociology, and environmental psychology. As a spatial concept it refers to a territorial location made up of buildings, landscape, and so forth, and may vary in scale from home, neighbourhood, community and beyond (Tuan, 1974). Here place is taken to refer to the phenomenal space located and experienced by individuals, a setting of social rootedness that ties together interpersonal interactions, and is constructed through social relations between people. This view emphasizes place:

“as 'open crossroads', a meeting place rather than an enclave of rest, a location with 'interactive potential' [...]. Whereas place understood as a stable, bounded and historically continuous entity corresponds to a traditional, conservative view of society, the concept of place as a source of potential social interactions better describes the features of the globalized world spaces of today" (Lewicka, 2011, p. 210).

In a similar vein, Canter (1991) moved beyond the individual representation of place and its physical setting toward the notion of place as a social process that involves group-based behavioural rules (see reviews by Agnew, 2011; Lewicka, 2011).

This social perspective of place sheds light on immigrants' experience in carving out a bicultural social space made up of a social network of host nationals and a second social network of host compatriots 
in the place of residence. Using transnational connectivity between place of residence and place of origin, immigrants may enrich the bicultural social space through connection to home compatriot networks forming a transnational bicultural place. The transnational bicultural place of Hong Kong (HK) Chinese immigrants in United Kingdom (UK), for example, would consist of UK British, UK Chinese, and HK Chinese networks. Given the spread of globalisation and ease of long-distance travel and communication, immigration nowadays has become less a clear break from home and more a form of living and working in which transnational connectivity between destination and home plays an increasingly prominent role (Dahinden, 2009; Vertovec, 1999). The model of transnational bicultural place to be developed below captures this modern transnational element as compared to earlier models that focus only on social networks in the place of residence (Nguyen \& Benet-Martínez, 2013). Applying the model to Hong Kong Chinese immigrants in Britain, who are a significant part of the British ethnic minority population (Office for National Statistics, 2009), the present study offers a fuller account of the impact of immigrants' overall social networks on their dual cultural self-concepts (i.e. British and Chinese cultural selves) and sense of being a citizen of Britain. In doing so it also advances the field of psychological citizenship (Sindic, 2011; Weeks, 1917) beyond monocultural assumptions to reveal immigrants' sense of transcultural citizenship.

\subsection{Transnational bicultural place}

Chinese immigrant communities have been traditionally perceived to be well-dispersed in the place of residence. Population dispersal was required to avoid market saturation when the predominant trade of Chinese immigrants was food takeaway businesses (Owen, 2006). Chinese immigrants have been shown to retain a distinct Chinese cultural identity (Chau \& Yu, 2001), and often remain in separate enclaves from the host community (Zhou, 2009). One explanation for this is that within Chinese culture, the family is considered the cornerstone of society (Chi, Chappell, \& Lubben, 2001). Caring practices are perceived to operate predominantly at the family level, with mutual help at the community level to be at a minimum 
(Chan, Cole, \& Bowpitt, 2007). One place that draws the Chinese community together is Chinatown, an ethnic enclave made up of local Chinese businesses, restaurants and food shops that remind immigrants of home (Anderson, 1987). In the UK, Chinatowns are present in all major cities with a large Chinese immigrant population, for example, London, Manchester and Liverpool.

Chinese immigrants in the UK form local social network ties with UK Chinese and UK British. In doing so, they move beyond making "bonding social capital” from ethno-linguistically homogeneous UK Chinese to forging "bridging social capital" with ethno-linguistically heterogeneous UK British (Putnam, 2000), thereby transforming the place of residence into a bicultural social world. Research so far has focused on these two host networks and rarely considered the significance of the social network of home compatriots (Nguyen \& Benet-Martínez, 2013). A similar oversight is evident in research on international students (Henderick, Rosen, \& Aune, 2011). Given the spread of globalization, instantaneous internet communication and affordable air travel between the UK and Hong Kong, Chinese immigrants are able to keep alive their network of Hong Kong compatriots, whom they have found helpful when they resettle back in Hong Kong (Waters, 2008). Therefore, it is timely to investigate all three networks, which collectively constitute immigrants' transnational bicultural place, a social space that links the near-by and the remote environments for meaningful social engagement that would shape their dual cultural selves and transcultural sense of citizenship.

\subsection{Psychological citizenship}

Immigrants expect to "have a better life" more earnestly than to become citizens in the host country. However, their sense of being (or not being) a citizen of the host country is just as important as their individual betterment from the point of view of immigration policy, national identity and societal cohesion (Gilchrist, Bowles, \& Wetherell, 2010). This sense of being a citizen has been referred to as "psychological citizenship" (e.g., Sindic, 2011), in contradistinction to civic, political, ecological and other forms of 
citizenship that have received research attention from sociologists and political scientists (Condor, 2011). According to Sindic (2011), a central feature of psychological citizenship is a sense of community belongingness and membership:

“Conceptually ..., if citizenship is a status accorded in virtue of belonging to a specific political community, then it follows that people need to see such community as actually corresponding to their community if their objective status of citizen is to have any psychological resonance. That is, it implies the feeling that the scope of the institutions of citizenship corresponds to one's community, and that one is a legitimate member of that community (i.e. the community is part of one’s self-definition).” (p. 203, original italics)

A second defining feature of psychological citizenship is keeping permanent or long-term residence as opposed to sojourning. Residence length has been extensively studied by environmental psychologists and found to be reliably correlated with community and place attachment (Boğaç, 2009; Hummon, 1992). For some researchers, residence length has been a key or sole measure of the attachment to place (Lewicka, 2011). It can also differentiate long-term stayers (whose attachment is based on social reasons and reflects loyalty) from sojourners or seasonal visitors, who may still claim attachment, but whose attachment is based more on the attractiveness or memorability of physical features of the community/place (Jennings \& Krannich, 2013). For these two reasons, residence length is an appropriate attribute for defining psychological citizenship. Together these affective (community belongingness) and behavioural (residence length) elements provide a useful basis for understanding that part of psychological citizenship that is common to host nationals and immigrants, but on their own underplay features that are relatively unique to the experience of immigrants.

Research on migration and transcultural identities has shown that for immigrants, becoming psychological citizens of the host community does not have to mean monocultural assimilation, for they have the option of transcending monoculturalism (Mirdal \& Ryynänen-Karjalainen, 2004). In the UK, 
“Appeals to an overarching, or inclusive, 'Britishness' generally have little traction in these situations. Especially when couched in terms of multicultural citizenship, this model of nationality overlooks the evident discrimination and disgruntlement experienced by many communities ... [and] many people subscribing to dual or hyphenated identities, such as Welsh Muslim, black British or Scots British.” (Gilchrist et al., 2010, p. 35). A vivid description of a similar mentality can be found in an early book entitled “The psychology of citizenship” (Weeks, 1917, p. 186):

"It is necessary that parochialism and provincialism be done away with, and that a ruinous patriotism, out of which conflicts and hatreds rise, be dispossessed by world consciousness."

The mentality of citizenship described by Weeks (1917) is a sense of humanity that transcends parochialism and embraces transnationalism, which can provide immigrants with a wider range of alternatives for life in their new country. One such alternative is “transnational integration or 'integration” into two societies," in which immigrants combine "cultural maintenance with constructive contacts with both their host country and their country of origin" and through which "they may develop a sound form of biculturalism or bicultural competence" (Oudenhoven \& Ward, 2013, p. 90). According to LaFromboise, Coleman, and Gerton (1993), biculturalism may take various forms such as fusion, hybrid, blended and alternating biculturalism. Of these, the blended and alternating forms of biculturalism are especially relevant here. Blended biculturalism is the construction (or reconstruction) of self as being a blended or combined product of host and heritage cultures. Alternating biculturalism is also known as bicultural efficacy or competence, which refers to immigrants' beliefs in their ability to adjust behaviour in accordance with the particular cultural norms of the social context and to maintain a positive relationship with both their heritage and host cultures and to be free to move between them without feeling conflict. The study of psychological citizenship among immigrants affords researchers the opportunity to move beyond community belongingness and residence length in a monocultural setting (as would be the case of host nationals) towards community belongingness and residence length that co-exist with blended biculturalism and 
bicultural efficacy. Community belongingness, residence length, blended biculturalism and bicultural efficacy will form a 4-item scale that measures psychological citizenship to test the effects due to social networks and dual cultural selves (see Sections 1.3 and 1.4) ${ }^{1}$. The theoretical question is not merely what makes psychological citizenship possible among immigrants, but also its transcultural basis. The answer, we propose, lies in immigrants' dual British and Chinese cultural selves that in turn require immigrants' trio of social networks in the transnational bicultural place for their development and maintenance.

\subsection{Dual cultural selves and their direct effects on psychological citizenship}

Acculturation psychology has shown that immigrants' acculturation is not merely taking on a second (host) culture as if it has nothing to do with the first (heritage) culture, but rather should be seen as an engagement in the twin processes of becoming competent members of and identifying with both cultures (Phinney, 2003; Sam \& Berry, 2006). Depending on their personal orientations toward the two cultures, immigrants may seek integration (positive about both cultures), assimilation (positive about the host but negative about the heritage culture), separation (reverse of assimilation), or marginalisation (negative about both cultures) (Berry, 2009). Nguyen and Benet-Martínez (2013) proposed the notion of "having two cultures" and concluded, on the basis of a meta-analysis of 83 studies, that having two cultures is positively and significantly associated with psychological and sociocultural adjustment, and that this association is stronger than that between adjustment and having just one culture. Whilst the notion of having two cultures may appear similar to integration, its stress is on processes whereby immigrants embody or incorporate

\footnotetext{
1 The authors acknowledge that there are other attributes of citizenship that have not been covered in the present discussion, including trust, voting, patriotism, citizen duties, and belief in universal human rights (Bolzendahl \& Coffé, 2013; Dalton, 2008; $\mathrm{Ng} \&$ Lai, 2011). These and others have been selectively used in the literature for defining political citizenship and other forms of citizenship such as civic, social, cultural, ecological and cosmopolitan/world citizenship (Condor, 2011; Isin \& Turner, 2002). They are potentially useful for an expanded version of the psychological citizenship scale in future research.
} 
aspects of the host and heritage culture into their overall self-concepts. The present study extends this line of thinking with the notion of dual cultural selves and proposes direct causal links between these selves and psychological citizenship.

Cultural self is that part of a person's overall self-concept based on, first, identification with the culture that he or she has come into contact with, and second, internalised cultural influence as reflected in cultural practices and tastes (reading and eating habits, keeping of festivals, etc.). This bi-dimensional approach to cultural self is partly based on social identity theory (Tajfel \& Turner, 1986), which stresses the role of group-based identity in the self-concept, and more generally on the dynamic constructivist view of self (Hong, Ip, Chiu, Morris, \& Menon, 2001). The latter view focuses not only on identity, but also on internalised cultural influences ranging from cultural knowledge to cultural values and cultural practices (Ng, Yam, \& Lai, 2007; Schwartz, Unger, Zamboanga, \& Szapocznik, 2010). Cultural self so defined can be seen as the accumulation of cultural capital through the embodiment (incorporation) of cultural identity, practices and tastes in the self-concept (Bourdieu, 1986). Lewicka (2013, p. 52) used the example of reading to show that a person's cultural capital can enhance his or her cultural adaptation: "Through reading one virtually appropriates new places, hence it may as well be that people who draw pleasure from reading books, particularly novels and books written by foreign authors, will show less "provincial" attitude when encountering new places, will be more curious about new environments, and will be endowed with better adaptation skills than those who don't have such virtual experience." For immigrants the embodiment of cultural capital is complicated (and enriched) by their transcultural experience that may lead them to expand their (heritage) cultural self-concept through identifying with and internalising aspects of the host culture. The resultant dual cultural selves, in light of Nguyen and Benet-Martínez's (2013) meta-analysis, would enhance cultural adjustment and for this reason would provide the psychological condition for (transnational) psychological citizenship. Pulling these ideas together we hypothesise that for Chinese immigrants in the UK, their British (Hypothesis 1) and Chinese (Hypothesis 2) cultural selves would both 
contribute directly to their psychological citizenship. Which of the two selves has greater impact remains an empirical question. The intergroup contact thesis (Hewstone \& Swart, 2011; Pettigrew \& Tropp, 2006) and the interactive acculturation model (Bourhis, Barrette, El-Geledi, \& Schmidt, 2009; Bourhis et al., 1997), both of which stress the role of the (dominant) host group in the acculturation process (see Section 1.4 below), would suggest a greater role for the British cultural self. By testing the effects of the two cultural selves separately, the present study will provide useful albeit post hoc results to throw light on the relative impact of the British and Chinese cultural selves.

\subsection{Social networks and their direct effects on dual cultural selves}

Psychological citizenship and dual cultural selves are mental functions. In proposing the two hypotheses in section 1.3, we subscribe to an individual (intrapsychic) level of explanation that views one mental function as the cause of another mental function. At best this can only lead to a limited understanding of psychological citizenship. A fuller understanding would also require a social, inter-individual level of explanation (Doise, 1986). In his model of psychological citizenship, Moghaddam (2008) applied Vygotsky's (1978) theory of the social mind and argued that rather than treating the development of psychological citizenship as if it were independent from the cultural context, it should be seen first on the social level as between individuals, and later on the personal (intrapsychic) level inside the individual. In a similar vein, Berry (2009) commented that the success of immigrants in achieving biculturalism would depend not only on their personal acculturation strategy of integration (see Section 1.3), but also on the reciprocal positive orientation of the dominant group towards immigrants. Bourhis and his associates combined these two sets of immigrant and dominant group orientations and proposed a social-level interactive acculturation model, which stresses the importance of viewing biculturalism in an intergroup perspective that recognizes the power of the dominant culture in setting limits to and defining the meaning of integration (Bourhis, Barrette, El-Geledi, \& Schmidt, 2009; Bourhis et al., 1997). Within this macro 
structure of power relations, immigrants' social networks in their transnational bicultural place offer a micro social environment for immigrants to acquire dual cultural selves.

In a general sense, social network is the web of person-centred social ties affiliated with kin, neighbours, workmates and so forth (Berkman \& Glass, 2000). All existing social ties, taken together, constitute the global network, among which the subsets of closer, personal ties are referred to as the personal network (van der Poel, 1993). Over a person's life course, the composition, size and quality of social networks change in tandem with different stages of life and specific life events such as migration; amidst the changes a convoy of family members and close confidants remains fairly stable to the end although some may be living away (Wrzus, Hänel, Wagner, \& Neyer, 2013).

Social ties within a network are a major source of social capital (Putnam, 2000), and can be accessed/ mobilised to provide social support in the form of practical help, emotional sustenance, information, and so forth. In a substantial review of the literature, Cohen and Wills (1985) draw the conclusion that a social network is beneficial not only because the social ties therein are perceived to be a reliable source of social support, but also beneficial by imparting a sense of social integration or belongingness to the group that it represents or symbolises. Other researchers have also pointed out that individuals in social networks are endowed with identities by virtue of their associations with and activities in them (Watts, Dodds, \& Newman, 2002). This leads us to propose that immigrants with bicultural social networks that are strong (in terms of size and quality) are more likely to form dual cultural selves (which in turn would promote psychological citizenship as already proposed in Hypotheses 1 and 2 in section 1.3). For reasons below, the link between particular social network and cultural self is expected to be along ethnic lines, that is, the social network of British host nationals would be associated with British cultural self, whereas the two social networks of Chinese compatriots would be associated with Chinese cultural self.

Across a large number of studies on intergroup contact, the overall results show that contact with the dominant (host) group has a positive effect on better mutual understanding and respect (Hewstone \& Swart, 
2011; Pettigrew \& Tropp, 2006). As the development of immigrants' host cultural self requires conducive conditions, such as intergroup understanding and respect, these results point to a possible link between contact with host nationals and host cultural self. Thus a larger network of host nationals (dominant group) that affords more frequent intergroup contact would lead to a higher level of host cultural self. Furthermore it should be noted that the intergroup contact/communication literature (Gudykunst, 2005) also suggests that large networks would have limited effect unless they also have good qualities such as satisfaction of contact, ease of communication and personal importance to immigrants. When size and quality are considered together, a network of host national networks that is stronger in both aspects would be more likely to promote the development of the host cultural self compared to a weaker network. Hence it is hypothesised that there would be a positive relationship between immigrants' UK British network and their British cultural self (Hypothesis 3).

Studies on the enculturation of minorities show that as their heritage language and cultural practices/tastes are not routinely adopted in the host culture, their maintenance depends to some extent on social contact in ethnic enclaves, and socialising or re-socialising into compatriot networks (Kim \& Omizo, 2010). Enclaves and compatriot networks are also places where immigrants can achieve continuity of their heritage identity, which would be instrumental to the maintenance of heritage culture self overall (Main, 2013). For Chinese immigrants the importance of ethnic enclaves and compatriot networks is generally recognised in the literature referred to in section 1.1. Hence we propose that immigrants' UK Chinese network (Hypothesis 4) and Hong Kong Chinese network (Hypothesis 5) are expected to be positively associated with their Chinese cultural self.

\subsection{Summary of hypotheses}

To summarise, Chinese (H1) and British (H2) cultural selves are expected to have direct positive effects on psychological citizenship. Social network ties are expected to influence directly their 
corresponding cultural self, that is, UK British network would affect British cultural self (H3), whereas UK Chinese (H4) and Hong Kong (H5) networks would affect Chinese cultural self. Through their influence on dual cultural selves, social networks that constitute the transnational bicultural place would indirectly affect the formation of psychological citizenship. That is, in addition to the five hypothesised direct effects (H1 to H5), the transnational bicultural place model also postulates three indirect causal paths:

UK British social network $\rightarrow$ British cultural-self $\rightarrow$ Psychological citizenship (H6)

UK Chinese social network $\rightarrow$ Chinese cultural-self $\rightarrow$ Psychological citizenship (H7)

Hong Kong social network $\rightarrow$ Chinese cultural-self $\rightarrow$ Psychological citizenship (H8)

Note that the model does not postulate any direct effects of social networks on psychological citizenship. The five hypotheses on direct effects of social networks on dual cultural selves will be evaluated holistically through structural equation modelling (SEM), followed by Sobel tests of the three hypotheses of indirect effects on psychological citizenship. Age at immigration is included as a control variable in recognition of its possible effects on the focal variables as suggested by other studies (e.g., Böhlmark, 2008; Martinovic, Van Tubergen, \& Maas, 2009).

\section{Method}

\subsection{Sample}

A total of 272 Chinese immigrants aged 15 to 91 years $(\mathrm{M}=46.55$; $\mathrm{SD}=18.53)$ took part in the study. The sample was drawn mainly from London and Manchester, with a small percentage from neighbouring towns. More than half of the respondents were female (58\%). All respondents migrated directly from Hong Kong. The majority were born in Hong Kong (84\%), while the rest were born in mainland China and later moved to Hong Kong before migrating to the UK. Length of residence in the UK ranged from 1 to 58 years $(\mathrm{M}=21.35 ; \mathrm{SD}=15.14)$. Average age at immigration was 22.16 years $(\mathrm{SD}=11.06)$. Regarding educational 
attainment, $14 \%$ of respondents had the highest educational attainment of primary or less, $17 \%$ attained GCSEs, 16\% had A-levels as the highest educational attainment, while the remaining 53\% had an undergraduate or above as the highest educational attainment. One third of respondents were single (34\%), $53 \%$ were married, $7 \%$ were widowed, and the remaining $6 \%$ were separated or divorced.

\subsection{Questionnaire}

\subsubsection{Social networks}

The strength of each social network was measured on the bases of its overall quality and aggregate size of three sub-networks, namely, relatives, neighbours and friends. Five items gleaned from the literature were constructed for respondents to rate the quality of a network as a whole in terms of "easy to communicate with", “is helpful”, “is pleasant”, "is important to me now”, and "is important to me for the future” on a 5-point response format (Kim, 1978; Ward \& Rana-Deuba, 2000). Four items were adapted from the Lubben Social Network Scale (Lubben, Blozik, Gillmannet et al., 2006) to measure the size of each sub-network in terms of how many (relatives/neighbours/friends) do you "see at least once a month," "hear from at least once a month," "feel close to such that you could call on them for help," and "feel at ease with that you can talk about private matters?” The 12 items (4 questions x 3 subnetworks) were answered on a 5point response format ranging from "none" to " 10 or more people". These were added to the five quality items to form a network strength scale.

\subsubsection{Psychological citizenship}

Four items based on the literature reviewed in section 1.2 were used to measure psychological citizenship in terms of community belongingness ("It is important for me to feel being a member of the community”), residence length (years living in Britain adjusted for age), blended biculturalism (“I feel part of a combined Chinese and British culture"), and bicultural efficacy ("I feel I can move freely between the Chinese and British cultures without feeling any conflict”). Since length of residence was potentially 
confounded with age because long residence would be only possible among older immigrants, it was adjusted for age before analysis (Ng, Kam, \& Pong, 2005).

\subsubsection{Cultural selves}

Measures of cultural selves were adapted from those used in studies on ethnic Chinese in Hong Kong (Ng, Yam, \& Lai, 2007). Each cultural self was measured by items covering identity, and cultural practices/tastes that reflect the internalisation of cultural influence. For Chinese cultural self, there were three identity items ("I am Chinese," “I am Hong Kong Chinese," and "I am a Hongkonger”) plus an overall statement on "I feel the Chinese identity in me is strong ... weak." Chinese cultural influence covered six aspects of Chinese cultural practices/tastes of language proficiency and use, preference of Chinese newspapers and TV, observance of Chinese traditions and festivals, eating Chinese foods, and so forth, along with an overall evaluation of the influence of Chinese culture: "I feel the Chinese culture in me is strong ... weak." A corresponding set of items measured British cultural self. Note that instead of four identity items, only three British identity items were necessary: “I am British," "I am British Chinese," and "I feel the British identity in me is strong ... weak." The seven Chinese cultural practices/tastes items were reworded to reflect British cultural influence (see Table 2).

\subsubsection{Demographics}

The questionnaire also contained a number of items relating to personal characteristics, such as age and age at immigration, among others details of which are provided in section 2.1.

\subsection{Procedure}

The questionnaire was available for respondents in English and Traditional Chinese. It was translated by a bilingual academic and then back translated by a second bilingual academic to ensure accuracy. Afterwards it was piloted among 30 Chinese immigrants to improve wording and comprehensibility. All questionnaire items were self-rated on 5-point scales except for age, age at immigration, community 
belongingness and residence length. Community belongingness (see section 2.2 .2 above) was rated on a 6point scale from low to high. The scores were converted to a 5-point scale. Residence length was adjusted for age and converted to a 5-point scale (see section 3.2 below). Given difficulties in identifying specific minority groups, sampling was non-random and recruitment from NGOs and other diverse organisations catering for Chinese immigrants was deemed the best option (McClean \& Campbell, 2003). Specifically respondents were recruited from a selection of Chinese community centres, health centres and other Chinese organisations across London and Manchester, UK. Many of the organisations were identified using the Chinese Community Service Directory and invited to participate in the study by serving as a recruitment site for participants. All organisations were contacted by letter, telephone, or email. Respondents received a participant information sheet from the organisations concerned with detailed information about the study before providing informed consent. Both the participant information sheet and consent form were available in English and Traditional Chinese. The questionnaire was administered in person by a member of the research team or self-administered at the request of the respondent. In the former case, the interview was conducted after pre-organised social events at the organisations concerned, or in some cases by special appointment at the homes of the respondents.

\section{Results}

\subsection{Social networks}

As shown in Table 1, all three scales of social networks were reliable ( $a$ s $=.88$ to .93$)$. UK Chinese network was the strongest $(M=2.79)$, Hong Kong network less strong $(M=2.44)$ and UK British network the least strong $(M=2.05)$.

\section{Table 1}


Bivariate correlations, reliabilities, means and SDs of variables.

\begin{tabular}{|c|c|c|c|c|c|c|c|}
\hline & 1 & 2 & 3 & 4 & 5 & 6 & 7 \\
\hline 1. UK Chinese Social Network & - & & & & & & \\
\hline 2. UK British Social Network & $.17 * *$ & - & & & & & \\
\hline 3. HK Social Network & $.26 * * *$ & $.24 * * *$ & - & & & & \\
\hline 4. Chinese Cultural Self & $.20 * *$ & $-.22 * * *$ & .10 & - & & & \\
\hline 5. British Cultural Self & .03 & $.40 * * *$ & .08 & -.00 & - & & \\
\hline 6. Psychological Citizenship & $.13^{*}$ & $.45^{* * *}$ & .10 & .02 & $.66^{* * *}$ & - & \\
\hline 7. Age at Immigration & .02 & -.11 & $.21 * * *$ & $.15^{*}$ & $-.22 * * *$ & $-.41 * * *$ & - \\
\hline Number of items & 17 & 17 & 17 & 10 & 10 & 4 & 1 \\
\hline Cronbach's a & .88 & .93 & .91 & .75 & .85 & .60 & NA \\
\hline $\mathrm{N}$ & 254 & 253 & 255 & 247 & 251 & 248 & 258 \\
\hline Mean & 2.79 & 2.05 & 2.44 & 4.10 & 3.42 & 3.68 & 22.16 \\
\hline $\mathrm{SD}$ & .63 & .68 & .67 & .58 & .79 & .67 & 11.05 \\
\hline
\end{tabular}

Note: missing data deleted pairwise. NA $=$ Not applicable. Mean: $1=$ lowest, $5=$ Highest. $* p<.05 ; * * p<.01 ; * * * p<.001$

\subsection{Psychological citizenship}

For reasons already stated in Section 2.2.2, immigrants' length of residence was adjusted for the age of immigrants by regressing residence length on age to obtain regression residuals to replace the raw scores for analysis. The unstandardised residuals were then compressed to five points to be consistent with the 5-point response format of the other three psychological citizenship items. To confirm the factorial 
structure of the psychological citizenship scale, the four items were subjected to a principal component factor analysis. The results showed a one-factor solution (based on eigenvalue $>1$ and scree plot) that explained $46 \%$ of the variance. All four factor loadings were high (community belongingness $=.63$; residence length $=.51$; blended biculturalism $=.77$; bicultural efficacy $=.77$ ). On the basis of these results, all four items were included in the scale. The 4-item scale had an alpha coefficient of .60, not as high as the conventional level of .70 but one that was to be expected given the small number of items (Cortina, 1993). To check if the alpha coefficient was within the 95\% confidence interval, Iacobucci and Duhachek's (2003) SPSS syntax was applied to determine the interval. The results showed that the coefficient was firmly within the $95 \%$ confidence interval (interval $=.51$ to $.68, \mathrm{SE}=.04$ ). As shown in Table 1 , the overall mean of psychological citizenship was 3.68, which was on the positive end of the 5-point scale.

\subsection{Cultural selves}

The 21 items were factor-analysed using principal component analysis with varimax rotation, resulting in six factors with eigenvalue $>1$. The scree plot suggested that a 2-factor solution was optimal. As the item "I am a Hongkonger" was not loaded on either factor, the factor analysis was rerun with this item omitted. The analysis yielded five factors with eigenvalue $>1$. The scree plot suggested the retention of two factors explaining $40.13 \%$ of variance. The first factor was clearly a British cultural self factor made up of the 10 British-related items of identity and cultural practice/tastes. Its reliability was .85 . The second factor was clearly a Chinese cultural self factor made up of 10 corresponding Chinese items with a reliability of .75 (see Table 2). The strength of cultural self varied from medium (British, $M=3.42$ ) to very high (Chinese, $M$ $=4.10)$.

\section{Table 2}


Principal component factor analysis of Chinese and British cultural selves items.

Factor 1

British cultural self
Factor 2

Chinese cultural self

\section{Cultural Identities}

I am British

I am British Chinese

British identity overall

I am Chinese

I am Hong Kong Chinese

Chinese identity overall

Cultural Practices/Tastes

Use of English language

English newspapers and magazines

English TV

Western tradition and festivals

Western food

English oral proficiency

British cultural influence overall

Use of Chinese language

Chinese newspapers and magazines

Chinese TV

Chinese tradition and festivals

Chinese food

Chinese oral proficiency

Chinese cultural influence overall
.51

.33

.61

.04

.09

.06

.81

.83

.63

.59

.57

.83

.80

$-.17$

$-.06$

$-.26$

.05

.04

.10

.10

23.10
$-.14$

.12

$-.02$

.55

.43

.63

$-.05$

$-.01$

.17

.14

$-.08$

.00

.59

.53

.52

.60

.67

.58

.62

17.03 
Note: factor loadings $>.30$ are shown in boldface.

\subsection{Correlations among social networks, cultural selves, and psychological citizenship}

The bivariate correlations of all variables are shown in Table 1. The three networks were positively inter-correlated ( $r$ range $=.17$ to .26$)$. The two cultural selves were uncorrelated with each other $(r=-.00)$. Several significant correlations were found among the focal variables. British cultural self but not Chinese cultural self was positively correlated with psychological citizenship. UK Chinese network was positively correlated with Chinese cultural self and psychological citizenship. UK British network was positively correlated with British cultural self, negatively with Chinese cultural self, and positively with psychological citizenship. Finally Hong Kong network was not correlated with Chinese cultural self or psychological citizenship. Note that these correlations should be interpreted with caution as they might be confounded by age at immigration, which was correlated with most focal variables. When testing the hypotheses, age at immigration was controlled (see section 3.6 below).

\subsection{Testing of hypotheses}

The five hypotheses on direct effects were tested holistically by means of structural equation modelling (SEM). Age at immigration was treated as a control variable and allowed to correlate with the focal variables of social networks, cultural selves, and psychological citizenship. As the bivariate correlation between the two cultural selves was zero (see Table 2), the correlation between Chinese and British cultural selves was constrained to zero in SEM. Structural equation modelling was performed using LISREL 8.8. Other analyses were run on SPSS 20.

The three main indices of model fit were SRMR, RMSEA and CFI. These fit statistics would result in lower Type I error rates with acceptable costs of Type II error rates (Hu \& Bentler, 1999), and for these 
reasons would suit our research objective. As some respondents were deleted due to missing values in one or more variables, the final sample size was less than 250 and this called for a more stringent compliance with the indices (see Sivo, Fan, Witta, \& Willse, 2006). Their respective cut-off criteria were set at .08 or lower (SRMR), .06 or lower (RMSEA), and .95 or higher (CFI). Since tests of multivariate skewness and kurtosis indicated that the assumption of multivariate normality required for the conventional maximum likelihood estimation method was not met, robust maximum likelihood estimation was applied and the Satorra-Bentler scaled statistic $\mathrm{X}^{2}\left(\mathrm{~S}-\mathrm{BX}^{2}\right)$ was obtained (Satorra \& Bentler, 1994).

In the initial model, only the correlation between cultural selves was constrained to zero. Although other fit statistics indicated a good fit, the RMSEA value was higher than the acceptable criterion, S$\mathrm{BX}^{2}(1, N=191)=2.33, p=.127, \mathrm{SRMR}=.019, \mathrm{RMSEA}=.084, \mathrm{CFI}=.995, \mathrm{AIC}=56.33$. After dropping four non-significant paths, the revised model attained a better fit, $\mathrm{S}-\mathrm{BX}^{2}(5, N=191)=5.88, p=.318, \mathrm{SRMR}$ $=.033, \mathrm{RMSEA}=.031, \mathrm{CFI}=.996, \mathrm{AIC}=51.88$. The $\mathrm{AIC}$ value was smaller (hence better) in the revised model $(\mathrm{AIC}=51.88)$ than in the first model $(\mathrm{AIC}=56.33)$, and the difference exceeded 2.0, the conventional threshold for statistical significance (Burnham \& Anderson, 2004). Moreover, a non-significant chi-square change suggested that deletion of the non-significant paths did not significantly worsen the model fit, $\Delta \mathrm{S}-\mathrm{BX}^{2}(4)=3.82, p=.430$. Hence the more parsimonious revised model was preferred and accepted as the final model.

Figure 1 shows the significant path coefficients of the final model $(p<.05)$. All five hypotheses concerning direct effects were supported with significant positive path coefficients. As predicted, positive effects were found for the British cultural self (H1) and the Chinese cultural self (H2) on psychological citizenship. The effects of the UK British social network on the British cultural self (H3), and that of the UK Chinese (H4) and the Hong Kong (H5) social networks on the Chinese cultural self were all significant as predicted. 
Sobel tests were conducted to test the three hypothesised indirect effects of the three social networks on psychological citizenship mediated by cultural selves. The results revealed that the indirect effects of the two host social networks were significant: UK British social network $\rightarrow$ British cultural-self $\rightarrow$ Psychological citizenship $(B=.21, z=4.98, p<.001)$ and Chinese social network $\rightarrow$ Chinese cultural-self $\rightarrow$ Psychological citizenship $(B=.03, z=1.99, p=.046)$. The indirect effect of home compatriots in Hong Kong was not significant.

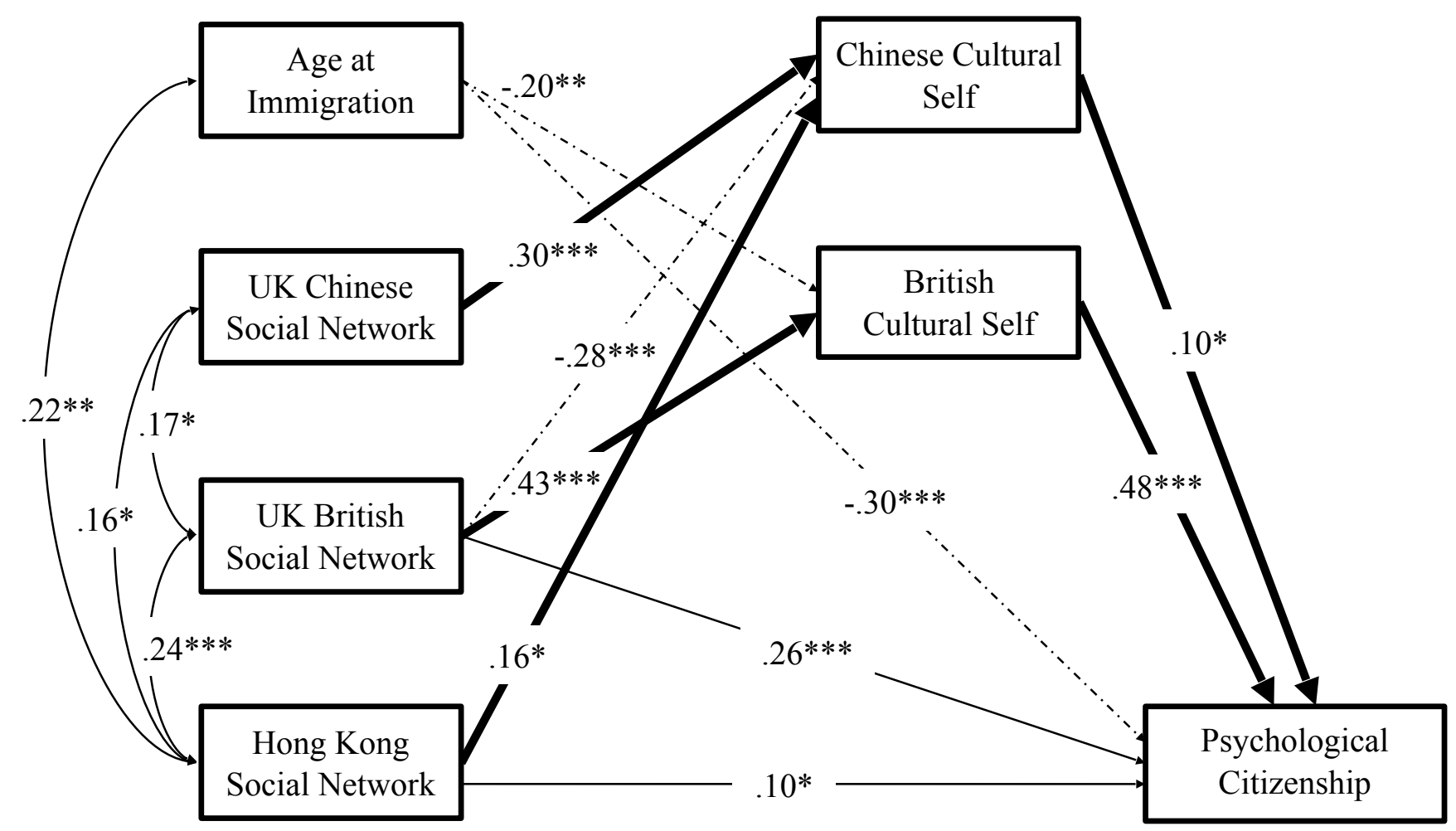

Figure 1. Final path model. $\mathrm{S}-\mathrm{Bx}{ }^{2}(5, N=191)=9.20, p=.101, \mathrm{SRMR}=.033, \mathrm{RMSEA}=.031, \mathrm{CFI}=.996$, $\mathrm{AIC}=51.88$. Paths shown are significant at $p<.05$. Solid lines: positive coefficients. Dotted lines: Negative coefficients. Bold lines: Predicted direct paths. ${ }^{*} p<.05 ; * * p<.01 ; * * *<<.001$. 


\subsection{Other results}

Six significant direct effects outside the hypotheses were found, five of which are shown in Figure 1. The UK British network impacted positively on psychological citizenship and negatively on the Chinese cultural self. The Hong Kong network impacted positively on psychological citizenship. Older age at immigration had a negative impact on British cultural self as well as psychological citizenship. Not shown in Figure 1 was a significant indirect negative path of older age at immigration $\rightarrow$ British cultural self $\rightarrow$ psychological citizenship $(B=-.10, z=2.91, p=.004)$.

The inter-correlations among networks and age at immigration showed two patterns of results. First, all three networks co-varied positively with each other, that is, immigrants tended to be highly or lowly connected with all networks rather than with one but not the others. Second, immigrants who left Hong Kong for Britain at an older age inherited a stronger Hong Kong network.

\section{Discussion}

\subsection{Evaluating the transnational bicultural place model}

After controlling for the effects due to age at immigration, the SEM results fully supported the five direct effect hypotheses. As predicted, all three social networks of the transnational bicultural place affected positively the corresponding cultural selves, which in turn affected positively psychological citizenship. On the other hand, Sobel tests showed that only two of the three hypothesised indirect effects of social networks on psychological citizenship were significant (UK British and UK Chinese networks); that of the Hong Kong networks was not. The missing indirect effect of Hong Kong network on psychological citizenship was largely due to the small (but still significant) effect of this network on Chinese cultural self (see Figure $1)$.

A key assumption of the present model was that the two cultural selves should be relatively 
independent of each other to allow for their respective direct effects on psychological citizenship and their corresponding associations with the host and compatriot networks. In support of the assumption, British and Chinese cultural selves were uncorrelated, which is consistent with the literature on multiple selves (McConnell, Shoda, \& Skulborstad, 2012), the multidimensional (vs. linear) view of being bicultural (Phinney, 1990), and similarly uncorrelated results reported for Chinese in Hong Kong (Ng \& Lai, 2011; Ng et al., 2007). For the sample as a whole, the mean level of British cultural self was lower than that of Chinese cultural self but still above the scale midpoint. The overall results provided substantial though incomplete support for the model of transnational bicultural place.

\subsection{Extending the transnational bicultural place model}

The SEM results reveal several results not addressed in the model. For discussion purposes they will be grouped under three subsections as follows.

\subsubsection{Greater influence of the British culture}

Though not predicted by the model, the direct effect of the UK British network on psychological citizenship was significant (.26). By contrast the direct effect of the UK Chinese network was nonsignificant. According to the intergroup contact thesis and the interactive acculturation model (see Section 1.4, also Brown \& Zagefka, 2011 and Tajfel, 1978), the comparative result would indicate the greater power of the dominant UK British culture in setting limits to and defining the meaning of transcultural psychological citizenship. Within this macro structure of power relations, immigrants' personal network of host nationals offered a micro social environment for them to develop community belongingness and willingness to stay, both of which were integral to psychological citizenship. Minority UK Chinese compatriots, on the other hand, did not have the same power and hence were less able to influence psychological citizenship. This explanation is consistent with the parallel finding that it was the cultural self 
based on the majority group (British cultural self) that played a greater role in psychological citizenship than that of the Chinese cultural self based on the minority Chinese group (.48 versus .10). The greater influence of the British culture suggests that within immigrants' overall experience of biculturalism, assimilation toward the host culture was a dominant strategy of acculturation.

\subsubsection{Pressure toward separation?}

The SEM results reveal a negative effect of UK British network on Chinese cultural self (-.28). This intriguing finding might reflect immigrants' perception of low acceptance of cultural diversity in British society, and those who were immersed in a strong British network might then have conformed to this perception by lowering their heritage cultural self. This explanation assumes that social network was the cause of the negative relationship between the UK British network and Chinese cultural self. However the reverse direction of causality cannot be ruled out: why should immigrants' Chinese cultural self keep them away from the UK British network? According to social identity theory (Tajfel \& Turner, 1986) and Mok et al. (2007), the reason might be due to immigrants' desire to safeguard their psychological distinctiveness as Chinese by disassociating themselves from the UK British network. To accommodate this possibility, the present model should be revised to take into account the bidirectionality of causal influence.

Irrespective of the direction of causality, the negative relationship between UK British network and Chinese cultural self raises serious questions on immigration policy goals and suggests the presence of pressure toward separation. In a study of Chinese immigrants in Northern Ireland, de Saissy (2009) urged consultations with the immigrants to identify appropriate immigration policy goals and strategies: "If integration is the adoption of the host society's culture while simultaneously retaining one's own, then would that not logically lead to the conclusion that well integrated Chinese immigrants in Northern Ireland are those who choose segregation and separation as the most effective acculturation strategy?" (p. 299). Whilst the present negative relationship between UK British network and Chinese cultural self may lend 
support to separation, its interpretation should be viewed with caution because the UK British network also contributed positively to a sense of transcultural citizenship.

\subsubsection{Division of roles between the UK Chinese and Hong Kong Chinese social networks}

With respect to the Chinese cultural self, the UK Chinese social network was more influential than the Hong Kong social network (.30 versus .16), suggesting that it was the immediate reference group or psychological in-group (Tajfel \& Turner, 1986) of UK Chinese rather than the physically remote group of Hong Kong Chinese that underpinned the Chinese cultural self. By contrast, psychological citizenship was affected directly and significantly by the Hong Kong network, but the effect due to the UK Chinese network was non-significant. This may be understood in terms of transnationalism, which refers to "multiple ties and interactions that link people or institutions across the borders of nation-states" (Vertovec, 1999, p.447). Snel, Engbersen and Leerkens (2006) found that different groups of immigrants residing in the Netherlands reported that transnational activities in the form of economic, political and sociocultural activities constitute a substantial element of immigrants' lives, allowing them to feel being free to move between the places of residence and origin. A nationwide survey of immigrants in Finland found evidence of the protective effect of home compatriots on the well-being of those immigrants who had experienced discrimination in the host country (Jasinskaja-Lahti, Liebkind, Jaakkola, \& Reuter, 2006). Apart from the literature on transnationalism, studies on transnational migration (Levitt \& Jaworsky, 2007) and return migration (Szkudlarek, 2010) have shown that immigrants nowadays move more frequently between their places of residence and origin, many of whom in fact resettle back in the latter. Such transnational and return migration activities could be facilitated if immigrants have a strong network back home and perhaps for this reason would feel more integrated inter-culturally and more efficacious in moving between two cultural worlds. Waters (2008) interviewed Hong Kong Chinese returnee students from Canada and found that their Hong Kong social network eased their return to Hong Kong by helping them gain recognition of their 
Canadian educational titles and associated cultural experience. These studies suggest that the Hong Kong network, in playing the role of transnational connecteivity, might have promoted a transcultural sense of citizenship. It should be noted, however, that the effects of the Hong Kong network were relatively small compared to those of the UK British network, and hence the importance of transnational connectivity in immigrants' life should not be over-estimated.

\subsection{Limitations}

The present findings, though sufficiently clear and coherent, are subject to several limitations. First, other aspects of psychological citizenship beyond community belongingness, residence length, blended biculturalism and bicultural efficacy remain to be explored. McBeth, Lybecker, and Garner (2010) made an interesting distinction between engaged and duty-based forms of participation. One future direction of psychological citizenship research that is especially relevant to immigrants is to track the transition from duty-based to engaged participation, relate this to their sense of citizenship duties and rights (Coffé \& Bolzendahl, 2013), and look for possible differences between age cohorts (Goodman, Bastedo, \& Pammett, 2011).

A second limitation is the one-time survey design, which is inherently incapable of determining the direction of causality (Wrzus et al., 2013). Third, as the findings were based on a non-representative sample of Chinese immigrants mainly in metropolitan London and Manchester, sampling limitation would restrict the extent to which they could be generalised to others living in smaller towns. Because participants were recruited from Chinese NGOs, this could have biased the results towards over-emphasising the effects of the UK Chinese social network relative to the UK British network. However, the results showed clearly that it was the UK British network that had stronger and more pervasive effects on psychological citizenship and cultural selves. The fourth limitation, which was inherent in the questionnaire methodology, was the oversight of the interactional process of bicultural self negotiation and presentation in daily interactions 
(Liu, 2011). The present study was silent on how immigrants actually managed their bicultural "I" and navigated between the two cultural worlds. Nor has it compared the social experience associated with biculturalism relative to that of the assimilationist strategy of acculturation whereby immigrants would single-mindedly develop their British cultural self without spending time or effort on maintaining their Chinese cultural self. Such comparison would be valuable in light of research showing the extra costs of biculturalism adversely affecting immigrants’ school performance (Gülseli, Phalet, \& Brown, 2011).

The fifth limitation was the oversight of individual differences that might affect social networking. The case in point was the interesting finding that immigrants' social networks were positively intercorrelated. This generalised tendency might be due to social motivations such as the need for affiliation or belonging (Baumeister \& Leary, 1995). Immigrants with a strong need for belongingness might have been motivated to form strong networks across ethnic boundaries and to maintain a strong network despite physical separation. Another possible factor was personality. For example, Pollet, Roberts, and Dunbar (2011) found that extroverts had larger networks across a range of network types, although they were not emotionally closer to network members. It would be interesting for future research to look into these factors and relate them to intercultural competence (Chen \& An, 2009).

Finally the present study has no qualitative and photographic data to bring out the physical aspects of the transnational bicultural place such as climate, landscape, transport, housing, culturally friendly public space, "Chinatown" and so forth. Consequently it falls short of an integrated study that would otherwise meld the social with the physical (Low \& Altman, 1992; Shin, 2013). This clearly is a challenging task for future research, much more difficult to accomplish than case studies that meld the social to a specific place with well-defined physical parameters such as a dwelling, an elderly home, a local neighbourhood, or a Chinatown.

\subsection{Conclusions}


By systematically showing how the three social networks that made up Chinese immigrants' transnational bicultural place supported their British and Chinese cultural selves, which in turn formed the mental basis of psychological citizenship, this study advances the understanding of migration and transcultural identities in a globalized world of population movement. Within this general contribution, the study makes another contribution of a more specific nature by separating the respective roles of the three social networks, as well as the respective roles of dual cultural selves, in the process whereby immigrants become psychological citizens with a broader transcultural consciousness. A less comprehensive design that omits one or more social networks, or only studies one of the two cultural selves, would have resulted in a less complete picture. The contributions are timely given the ascendancy of transnationalism (Oudenhoven \& Ward, 2013; Vertovec, 1999), the need of moving the study of psychological citizenship beyond the narrow assumption of monoculturalism (Weeks, 1917), the expansion of social network research in the social science literature (Borgatti, Mehra, Brass, \& Labianca, 2009), and researchers' interest in the re-entry process of return migration (Szkudlarek, 2010; Tabor \& Milfont, 2011).

\section{References}

Agnew, J. A. (2011). Space and place. In J. A. Agnew \& D. N. Livingstone (Eds.), Handbook of geographical knowledge (pp. 316-330). London: Sage.

Anderson, K. (1987). The idea of Chinatown: The power of place and institutional practice in the making of a racial category. Annals of the Association of American Geographers, 77, 580-598. doi: 10.1111/j. 1467-8306.1987.tb00182.x

Baumeister, R. E., \& Leary, M. R. (1995). The need to belong: Desire for interpersonal attachment as a fundamental human motivation. Psychological Bulletin, 117, 497-529. doi: 10.1037/0033-2909.117.3.497

Berkman, L. F., \& Glass, T. (2000). Social integration, social networks, social support, and health. In: L. F. 
Berkman \& I. Kawachi (Eds.), Social epidemiology (pp. 137-173). New York: Oxford University Press.

Berry, J.W. (2005). Acculturation: Living successfully in two cultures. International Journal of Intercultural Relations, 29, 697-712. doi: 10.1016/j.ijintrel.2005.07.013

Berry, J. W. (2009). A critique of critical acculturation. International Journal of Intercultural Relations, 33, 361-371. doi: 10.1016/j.ijintrel.2009.06.003

Boğaç, C. (2009). Place attachment in a foreign settlement. Journal of Environmental Psychology, 29, 267278. doi:10.1016/j.jenvp.2009.01.001.

Böhlmark, A. (2008). Age at immigration and school performance: A siblings analysis using Swedish register data. Labour Economics. 15, 1366-1387. doi: 10.1016/j.labeco.2007.12.004

Bolzendahl, C., \& Coffé, H. (2013). Are ‘Good' citizens 'Good' participants? Testing citizenship norms and political participation across 25 nations. Political Studies, 61, 45-65. doi: 10.1111/1467-9248.12010

Borgatti, S. P., Mehra, A., Brass, D. J., \& Labianca, G. (2009). Network analysis in the social sciences. Science, 323, 892-895. doi: 10.1126/science.1165821

Bourdieu, P. (1986). The forms of capital. In J. G. Richardson (Ed.), Handbook of theory of research for the sociology of education (pp. 241-258). New York: Greenwood Press.

Bourhis, R. Y., Barrette, G., El-Geledi, S., \& Schmidt, R. (2009). Acculturation orientations and social relations between immigrant and host community members in California. Journal of Cross-Cultural Psychology, 40, 443-467. doi: 10.1177/00220022108330988

Bourhis, R. Y., Moise, L. C., Perrault, S. \& Senecal, S. (1997). Towards an interactive acculturation model: A social psychological approach. International Journal of Psychology, 32, 369-386. doi: $10.1080 / 002075997400629$

Brown, R., \& Zagefka, H. (2011). The dynamics of acculturation: An intergroup perspective. Advances in Experimental Social Psychology, 44, 129-184. doi: 10.1016/B978-0-12-385522-0.00003-2 
Burnham, K. P., \& Anderson, D. R. (2004). Multimodel inference: Understanding AIC and BIC in model selection. Sociological Methods and Research, 33, 261-304. doi: 10.1177/0049124104268644

Canter, D. (1991). Understanding, assessing, and acting in places: Is an integrative framework possible? In G. W. E. Tommy Garling (Ed.), Environment, cognition, and action: An integrated approach (pp. 191209). New York: Oxford University Press.

Chan, C.K., Cole, B., \& Bowpitt, G. (2007). 'Beyond silent organisations': A reflection of the UK Chinese and their community organisations. Critical Social Policy, 27, 509-533. doi:

$10.1177 / 0261018307081810$

Chau, R.C.M., \& Yu, S.W.K. (2001). Social exclusion of the Chinese people in Britain. Critical Social Policy, 21, 103-125. doi: 10.1177/026101830102100103

Chi, I., Chappell, N.L., \& Lubben, J. (2001). Elderly Chinese in Pacific Rim Countries: Social support and integration. Hong Kong: Hong Kong University Press.

Coffé, H., \& Bolzendahl, C. (2013). Racial group differences in support for citizenship duties and rights in the US: Racial differences citizenship duties and rights. Acta Politica 48, 47-67. doi:10.1057/ap. 2012.22

Cohen, S., \& Wills, T. A. (1985). Stress, social support, and the buffering hypothesis. Psychological Bulletin, 98, 310-57. doi: $\underline{10.1037 / 0033-2909.98 .2 .310}$

Condor, S. (2011), Towards a social psychology of citizenship? Introduction to the Special Issue. Journal of Community and Applied Social Psychology, 21, 193-201. doi: 10.1002/casp.1089

Dahinden, J. (2009). Are we all transnationals now? Network transnationalism and transnational subjectivity: The differing impacts of globalization on the inhabitants of a small Swiss city. Ethnic \& Racial Studies, 32, 1365-1386. doi: 10.1080/01419870802506534

Dalton, R. J. (2008). Citizenship norms and the expansion of political participation. Political Studies, 56, 76-98. doi: 10.1111/j.1467-9248.2007.00718.x 
de Saissy, C. K. M. (2009). Acculturation, self-efficacy and social support among Chinese immigrants in Northern Ireland. International Journal of Intercultural Relations, 33, 291-300. doi: 10.1016/j.ijintrel. 2009.04.002

Doise, W. (1986). Levels of explanation in social psychology (translated by E. Mapstone), New York: Cambridge University Press.

Gilchrist, A., Bowles, M., \& Wetherell, M. (2010). Identity and social action: Connecting communities for a change. UK: Economic \& Social Research Council.

Goodman, N., Bastedo, H., LeDuc, L., \& Pammett, J. H. (2011). Young Canadians in the 2008 federal election campaign: Using facebook to probe perceptions of citizenship and participation. Canadian Journal of Political Science, 44, 859-881. doi:10.1017/S0008423911000783

Gudykunst, W. B. (Ed.) (2005). Theorizing about intercultural communication. Thousand Oaks, CA: Sage.

Gülseli, B., Phalet, K., \& Brown, R. (2011). Dual identity as a two-edged sword: Identity threat and minority school performance. Social Psychology Quarterly, 74, 121-143. doi:10.1177/0190272511407619

Henderick, B., Rosen, D., \& Aune, R. K. (2011). An analysis of friendship networks, social connectedness, homesickness, and satisfaction levels of international students. International Journal of Intercultural Relations, 35, 281-295. doi: 10.1016/j.ijintrel.2010.08.001

Hewstone, M., \& Swart, H. (2011), Fifty-odd years of inter-group contact: From hypothesis to integrated theory. British Journal of Social Psychology, 50, 374-386. doi: 10.1111/j.2044-8309.2011.02047.x

Hong, Y., Ip, G., Chiu, C., Morris, M. W., \& Menon, T. (2001). Cultural identity and dynamic construction of the self: Collective duties and individual rights in Chinese and American cultures. Social Cognition, 19, 251-268. doi:0.1521/soco.19.3.251.21473

Hu, L. T., \& Bentler, P. M. (1999). Cutoff criteria for fit indexes in covariance structure analysis: Conventional criteria versus new alternatives. Structural Equation Modeling: A multidisciplinary Journal, 6, 1-55. doi:10.1080/10705519909540118 
Hummon, D. M. (1992). Community attachment, local sentiment, and sense of place. In I. Altman \& S. M. Low, (Eds), Place attachment (pp. 253-278). New York: Plenum.

Isin, E. F., \& Turner, B. S. (Eds.) (2002). Handbook of citizenship studies. London: Sage.

Iacobucci, D., \& Duhachek, A. (2003). Advancing alpha: Measuring reliability with Confidence. Journal of Consumer Psychology, 13(4), 478-487. doi: 10.1207/ S15327663JCP1304_14

Jasinskaja-Lahti, I., Liebkind, K., Jaakkola, M., \& Reuter, A. (2006). Perceived discrimination, social support networks, and psychological well-being among three immigrant groups. Journal of Cross-Cultural Psychology, 37, 293-311. doi: 10.1177/0022022106286925

Jennings, B. M. \& Krannich, R. S. (2013). A multidimensional exploration of the foundations of community attachment among seasonal and year-round residents. Rural Sociology, 78, 498-527. doi: $10.1111 /$ ruso. 12019

Kim, B. S. K., \& Omizo, M. M. (2010). Behavioural enculturation and acculturation, psychological functioning, and help-seeking attitudes among Asian American adolescents. Asian American Journal of Psychology, 1, 175-185. doi: 10.1037/a0021125

Kim, Y. Y. (1978). A communication approach to the acculturation process: A study of Korean immigrants in Chicago. International Journal of Intercultural Relations, 2, 197-224. doi: $10.1016 / 0147-1767(78) 90006-8$

LaFromboise, T., Coleman, H. L. K., \& Gerton, J. (1993). Psychological impact of biculturalism: Evidence and theory. Psychological Bulletin, 114, 395-412. doi: $\underline{10.1037 / 0033-2909.114 .3 .395}$

Levitt, P., \& Jaworsky, B. N. (2007). Transnational migration studies: Past developments and future trends. Annual Review of Sociology, 33, 129-156. doi: 10.1146/annurev.soc.33.040406.131816.

Lewicka, M. (2010). What makes neighbourhood different from home and city? Effects of place scale on place attachment. Journal of Environmental Psychology, 30, 35-51. doi:10.1016/j.jenvp. 2009.05.004. 
Lewicka, M. (2011). Place attachment: How far have we come in the last 40 years? Journal of Environmental Psychology, 31, 207-230. doi: 10.1016/j.jenvp.2010.10.001

Lewicka, M. (2013). Localism and activity as two dimensions of people-place bonding: The role of cultural capital. Journal of Environmental Psychology, 36, 43-53. doi: 10.1016/j.jenvp.2013.07.002

Liu, S. (2011). Acting Australian and being Chinese: Integration of ethnic Chinese business people. International Journal of Intercultural Relations, 35, 406-415. doi: 10.1016/j.ijintrel.2010.04.004

Low, S. M., \& Altman, I. (1992). Place attachment: A conceptual inquiry. In I. Altman and S.M. Low (Eds.), Place attachment (pp. 1-12). New York: Plenum Press. DOI: 10.1007/978-1-4684-8753-4_1

Lubben, J., Blozik, E., Gillmann, G., Iliffe, S., von Renteln Kruse, W., Beck, J. C., \& Stuck, A. E. (2006). Performance of an abbreviated version of the Lubben Social Network Scale among three European community-dwelling older adult populations. Gerontologist, 46, 503-513. doi:10.1093/geront/ 46.4.503.

Main, K. (2013). Planting roots in foreign soil? Immigrant place meanings in an urban park. Journal of Environmental Psychology, 36, 291-304. doi: 10.1016/j.envp.2013.08.003

Martinovic, B., Van Tubergen, F., \& Maas, I. (2009). Dynamics of interethnic contact: A panel study of immigrants in the Netherlands. European Sociological Review, 25, 303-318. doi: 10.1093/esr/jcn049

McBeth, M. K., Lybecker, D. L., \& Garner, K. A. (2010). The story of good citizenship: Framing public policy in the context of duty-based versus engaged citizenship. Politics and Policy, 38, 1-23. doi: 10.1111/j.1747-1346.2009.00226.x

McClean, C.A., \& Campbell, C. (2003). Locating research informants in a multi-ethnic community: Ethnic identities, social networks and recruitment methods. Ethnicity \& Health, 8, 41-61. doi: $10.1080 / 1355785032000107977$

McConnell, A. R., Shoda, T. M., \& Skulborstad, H. M. (2012). The self as a collection of multiple self-aspects: Structure, development, operation, and implications. Social Cognition, 30, 380-395. doi: 
10.1521/soco.2012.30.4.380

Mirdal, G. M., \& Ryynänen-Karjalainen, L. (2004). Migration and transcultural identities: An ESF Standing Committee for the Humanities Forward Look Report (E-copy from: www.esf.org). European Science Foundation.

Mok, A., Morris, M. W., Benet-Martínez, V., \& Karakitapoğlu-Aygün, Z. (2007). Embracing American culture: Structures of social identity and social networks among first-generation biculturals. Journal of Cross-Cultural Psychology, 38, 629-635. doi: 10.1177/0022022107305243

Moghaddam, F.M. (2008). The psychological citizen and the two concepts of social contract: A preliminary analysis. Political Psychology, 29 (6), 881-901. doi: 10.1111/j.1467-9221.2008.00671.x

Ng, S.H., Kwong, P. K., \& Pong, R. W. M. (2005). People living in ageing buildings: Their quality of life and sense of belonging. Journal of Environmental Psychology, 25, 347-360. doi: 10.1016/j.jenvp. 2005.08.005

Ng, S. H., \& Lai, J. C. L. (2011). Bicultural self, multiple social identities, and dual patriotisms among ethnic Chinese in Hong Kong. Journal of Cross-Cultural Psychology, 42, 89-103. doi:

$10.1177 / 0022022110361715$

Ng, S. H., Yam, N., \& Lai, J. (2007). The bicultural self of Chinese in Hong Kong. In J. Liu, C. Ward, A. Bernardo, M. Karasawa, \& R. Fischer (Eds.), Casting the individual in societal and cultural contexts: Social and societal psychology for Asia and the Pacific (Progress in Asian Social Psychology Series, Vol. 6) (pp. 105-122). Seoul, Korea: Kyoyook-Kwahak-Sa.

Nguyen, A.-M. D., \& Benet-Martínez, V. (2013). Biculturalism and adjustment: A meta-analysis. Journal of Cross-Cultural Psychology, 44, 122-159. doi: 10.1177/0022022111435097

Office for National Statistics (2012). Ethnicity and National Identity in England and Wales in 2011. London: Office for National Statistics. Retrieved, from: http://www.ons.gov.uk/ons/dcp171776_290558.pdf Owen, D. (2006). Demographic profiles and social cohesion of minority ethnic communities in England and 
Wales. Community Work \& Family, 9, 251-272. doi: 10.1080/13668800600743552

Pettigrew, T. F., \& Tropp, L. R. (2006). A meta-analytic test of intergroup contact theory. Journal of Personality and Social Psychology, 90, 751-783. doi: $\underline{10.1037 / 0022-3514.90 .5 .751}$

Phinney, J. S. (1990). Ethnic identity in adolescents and adults: Review of research. Psychological Bulletin, 13, 499-514. doi: 10.1037/0033-2909.108.3.499

Phinney, J. (2003). Ethnic identity and acculturation. In K. Chun, P. Organista, \& G. Marin (Eds.), Acculturation: Advances in theory, measurement and applied research (pp. 63-81). Washington, DC: American Psychological Association.

Pollet, T. V., Roberts, S. G. B., \& Dunbar, R. I. M. (2011). Extraverts have larger social network layers: But do not feel emotionally closer to individuals at any layer. Journal of Individual Differences, 32, 161169. doi: $\underline{10.1027 / 1614-0001 / a 000048}$

Putnam, R. D. (2000). The collapse and revival of American community. New York: Simon \& Schuster.

Sam, D. L., \& Berry, J. W. (2006). Cambridge handbook of acculturation psychology. Cambridge: Cambridge University Press.

Satorra, A., \& Bentler, P. M. (1994). Corrections to test statistics and standard errors in covariance structure analysis. In A. Von Eye \& C. C. Clogg (Eds.), Latent variable analysis: Applications for developmental research (pp. 399-419). Thousand Oaks, CA: Sage.

Schwartz, S. J., Unger, J. B., Zamboanga, B. L., \& Szapocznik, J. (2010). Rethinking the concept of acculturation: Implications for theory and research. American Psychologist, 65, 237-251. doi: $\underline{10.1037 /}$ $\underline{\mathrm{a} 0019330 .}$.

Shin, J-h. (2013). Making home in the age of globalization: A comparative analysis of elderly homes in the U.S. and Korea. Journal of Environmental Psychology, 37, 80-93. doi.org/10.1016/j.jenvp. 2013.12 .001 
Sindic, D. (2011). Psychological citizenship and national identity. Journal of Community and Applied Social Psychology, 21, 202-214. doi: 10.1002/casp.1093

Sivo, S. A., Fan, X., Witta, E. L., \& Willse, J. T. (2006). The search for “optimal” cutoff properties: Fit index criteria in structural equation modeling. Journal of Experimental Education, 74, 267-288. doi: 10.3200/JEXE.74.3.267-288

Snel, E., Engbersen, G., \& Leerkes, A. (2006). Transnational involvement and social integration. Global Networks, 6, 265-284. doi: 10.1111/j.1471-0374.2006.00145.x.

Schalz, R. T., Staub, E., \& Lavine, H. (1999). On the varieties of national attachment: Blind versus constructive patriotism. Political Psychology, 20, 151-174.

Szkudlarek, B. (2010). Reentry: A review of the literature. International Journal of Intercultural Relations, 34, 1-21. doi: 10.1016/j.jintrel.2009.06.006.

Tabor, A. S., \& Milfont, T. L. (2011). Migration change model: Exploring the process of migration on a psychological level. International Journal of Intercultural Relations, 35, 818-832. doi: 10.1016/j.jintrel. 2010.11.013.

Tajfel, H. (1978). The social psychology of minorities. London: Minority Rights Group.

Tajfel, H., \& Turner, J. C. (1986). The social identity theory of intergroup behaviour. In S. Worchel \& W. G. Austin (Eds.), Psychology of intergroup relations, $2^{\text {nd }}$ ed. (pp. 7-24). Chicago: Nelson-Hall.

Tuan, Y. F. (1977). Space and Place: The perspective of experience. Minneapolis, MN: University of Minnesota Press.

van der Poel, M.G.M. (1993). Delineating personal support networks. Social Networks, 15, 49-70. doi: 10.1016/0378-8733(93)90021-C.

van Oudenhoven, J. P., \& Ward, C. (2013). Fading majority cultures: The implications of transnationalism and demographic changes for immigrant acculturation. Journal of Community and Applied Social Psychology, 23, 81-97. doi: 10.1002/casp.2132. 
Vertovec, S. (1999). Migration, Diasporas and Transnationalism. Aldershot: Edward Elgar.

Vygotsky, L. S. (1978). Mind in society. Cambridge, MA: Harvard University Press.

Ward, C., \& Rana-Deuba, A. (2000). Home and host culture influences on sojourner adjustment. International Journal of Intercultural Relations, 24, 291-306. doi: 10.1016/S0147-1767(00)00002-X.

Waters, J. L. (2008). Education, migration, and cultural capital in the Chinese diaspora: Transnational students between Hong Kong and Canada. New York: Cambria Press.

Watts, D. J., Dodds, P. S., \& Newman, M. E. J. (2002). Identity and search in social networks. Science, 296, 1302-1305. doi: 10.1126/science.1070120.

Weeks, A. D. (1917). The psychology of citizenship. Chicago: A. C. McClurg \& Co. Retrieved from: https:// archive.org/stream/psychologycitiz03weekgoog\#page/n8/mode/2up

Wetherell, M. (Ed.) (2009). Identity in the 21st century: New trends in changing times. Basingstoke: Palgrave.

Wrzus, C., Hänel, M., Wagner, J., \& Neyer, F. J. (2013). Social network changes and life events across the life span: A meta-analysis. Psychological Bulletin, 139, 53-80. doi: 10.1037/a0028601.

Zagefka, H., \& Brown, R. (2002). The relationship between acculturation strategies, relative fit and intergroup relations: Immigrant majority relations in Germany. European Journal of Social Psychology, 32, 171-88. doi: 10.1002/ejsp.73

Zhang, J., \& Goodson, P. (2011). Acculturation and psychosocial adjustment of Chinese in t e r $n$ a t i o n a 1 students: Examining mediation and moderation effects. International Journal of Intercultural Relations, 35, 614-627. doi: 10.1016/j.intrel.2010.11.004

Zhou, M. (2009). Contemporary Chinese America: Immigration, ethnicity, and community transformation. Philadelphia, PA: Temple University Press. 